\title{
Does hypothermia versus normothermia after out-of-hospital cardiac arrest improve patient-oriented outcomes?
}

\author{
Alisha Greer ${ }^{1}$ (D) Bram Rochwerg $^{2,3} \cdot$ Sameer Sharif ${ }^{1,2}$ \\ Received: 22 July 2021 / Accepted: 23 September 2021 / Published online: 5 October 2021 \\ (c) The Author(s), under exclusive licence to Canadian Association of Emergency Physicians (CAEP)/ Association Canadienne de Médecine d'Urgence \\ (ACMU) 2021
}

Keywords Cardiac arrest $\cdot$ Hypothermia $\cdot$ Normothermia

Full citation: Dankiewicz J, Cronberg T, Lilja G, Jakobsen JC, Levin H, Ullén S, et al. Hypothermia versus Normothermia after Out-of-Hospital Cardiac Arrest. New England Journal of Medicine. 2021;384(24):2283-94.

Abstract Link: https://www.nejm.org/doi/full/10.1056/ NEJMoa2100591

Article type: Therapy

Ratings: Methods—4/5; Usefulness-4/5

\section{Introduction}

\section{Background}

Hyperthermia has been shown to be associated with worse neurologic outcomes post-cardiac arrest [1]. The Hypothermia after Cardiac Arrest (HACA) trial, published in 2002, showed better neurological outcomes in the therapeutic

Alisha Greer

alisha.greer@medportal.ca

1 Division of Emergency Medicine, Department of Medicine, McMaster University, Hamilton, ON, Canada

2 Division of Critical Care, Department of Medicine, McMaster University, Hamilton, ON, Canada

3 Department of Health Research Methods, Evidence and Impact, McMaster University, Hamilton, ON, Canada hypothermia group $\left(32{ }^{\circ} \mathrm{C}\right)$ as compared to those randomized to usual care in patients following out-of-hospital cardiac arrest (OHCA) (55\% vs 39\%) [2]. This led to the adoption of targeted temperature management (TTM) in patients following OHCA. Subsequently, the first TTM trial by Neilsen et al. compared $33^{\circ} \mathrm{C}$ vs. $36^{\circ} \mathrm{C}$ in OHCA patients, and showed no difference between the two temperature targets [3]. Thus, although TTM continues to be the standard of care in OHCA patients, the optimal temperature target remains uncertain.

\section{Objective}

To assess the beneficial and harmful effects of therapeutic hypothermia $\left(33^{\circ} \mathrm{C}\right)$ vs. targeted normothermia including early treatment of fever in patients who suffered OHCA of presumed cardiac or unknown cause.

\section{Methods}

\section{Design}

Multi-centre, single-blind, randomized superiority trial. This study was conducted at 65 hospitals across Europe, Australia, and North America.

\section{Subjects}

Adult patients over age 18 admitted to hospital after OHCA of presumed cardiac or unknown cause who were unconscious, not able to obey verbal commands and did not have verbal response to pain. Patients were excluded if pregnant, had known or suspected intracranial bleeding, had an unwitnessed arrest with initial rhythm of asystole, had an admission temperature below $30^{\circ} \mathrm{C}$, were receiving extracorporeal 
membrane oxygenation that was initiated prior to return of spontaneous circulation, or had severe COPD requiring home oxygen therapy.

\section{Intervention}

Therapeutic hypothermia with a target temperature of $33^{\circ} \mathrm{C}$. Cooling was initiated as rapidly as possible post-cardiac arrest by surface and/or intravascular devices.

\section{Comparison}

Targeted normothermia to $37.5^{\circ} \mathrm{C}$. Temperature was monitored and cooling was initiated if it reached a threshold above $37.8^{\circ} \mathrm{C}$. No intervention was provided if patient's body temperature was spontaneously below $37.5^{\circ} \mathrm{C}$.

\section{Primary outcome}

All-cause mortality assessed at 180 days after randomization.

\section{Secondary outcomes}

- Proportion of patients with a poor functional outcome at 180 days after randomization measured using the modified Rankin Scale (mRS 0-3 vs. 4-6).

- Number of days alive and outside hospital at 180 days after randomisation.

- Health-Related Quality of Life (HRQoL) using EQ5D-5L at 180 days after randomization.

- Time-to-event (survival). All participants were followed until the last included participant has been followed-up at 180 days. If death had not occurred, participants were censored at this point.

- Prespecified adverse events were pneumonia, sepsis, bleeding, arrhythmia resulting in hemodynamic compromise, and skin complications related to the device used for targeted temperature management

\section{Results}

In total, 930 patients were randomized to therapeutic hypothermia and 931 to normothermia. The hypothermia group had mortality of 50\% while the normothermia group had mortality of $48 \%$ (relative risk [RR] 1.04, 95\% confidence interval [CI] 0.94-1.14). The proportion of patients with mRS of 4 to 6 was $55 \%$ in both groups (RR 1.00, 95\% CI 0.92-1.09).

Arrhythmias resulting in hemodynamic compromise were more common in hypothermia group ( $24 \%$ vs. $17 \%$ ) (RR 1.45 , 95\% CI 1.21-1.75).

\section{Appraisal}

\section{Strengths}

- Large, multicentre, international randomized trial.

- Large proportion of patients with non-shockable rhythm; earlier studies of therapeutic hypothermia included mostly patients with shockable rhythms.

- Baseline characteristics similar between both groups.

- Cooling method not standardized and left to discretion of treating team, more pragmatic and reflective of actual practice.

\section{Limitations}

- Normothermia group heterogeneous given that some patients received cooling while others did not require intervention.

- Lack of true control group to evaluate whether targeted normothermia is superior to no temperature management.

- Risk of bias as healthcare providers were not blinded to intervention and may have contributed to a differential use of co-interventions.

- Limited to patients with OHCA due to cardiac or unknown cause and, therefore, uncertain generalizability to in-hospital cardiac arrests or out-of-hospital cardiac arrests due to alternative causes.

- Cooling was initiated as soon as possible, however, the median time to achieving hypothermia was $3 \mathrm{~h}$ after return of spontaneous circulation. This delay in cooling may lessen any positive effect of therapeutic hypothermia.

- This study did not evaluate mild hypothermia $\left(36^{\circ} \mathrm{C}\right)$ which is more commonly used in the post-TTM- 1 era. It is possible that the increased adverse events seen with more aggressive hypothermia $\left(33^{\circ} \mathrm{C}\right)$ could confound potential benefit seen with TTM.

\section{Context}

Therapeutic hypothermia to $32-33{ }^{\circ} \mathrm{C}$ was associated with improved neurologic outcomes and decreased mortality after cardiac arrest in the Bernard and HACA studies (Table 1) $[2,4]$. These initial studies enrolled fewer patients and only those who had ventricular fibrillation. The original TTM trial showed no difference in neurological outcomes between cooling to $33{ }^{\circ} \mathrm{C}$ vs. $36{ }^{\circ} \mathrm{C}$ (Table 1 ) but there was a signal towards fewer complications using the higher target [3]. Advances in critical care management over the last 20 years may account for the lack of difference seen with therapeutic 
Table 1 Comparison of characteristics and primary outcomes of the HACA, TTM, and TTM-2 trials

\begin{tabular}{|c|c|c|c|}
\hline Trial & Sample size & Mortality & Unfavourable neurologic outcome \\
\hline HACA [2] & 137 & $\begin{array}{l}32-34{ }^{\circ} \mathrm{C} \\
56 / 137(41 \%) \\
\text { Normothermia } \\
76 / 138(55 \%) \\
\text { RR } 0.74(95 \% \text { CI } 0.58-0.95)\end{array}$ & $\begin{array}{l}\text { CPC score } 3 \text { or } 4 \\
32-34{ }^{\circ} \mathrm{C} \\
61 / 136(45 \%) \\
\text { Normothermia } \\
83 / 137(61 \%) \\
\text { RR } 1.40(95 \% \text { CI } 1.08-1.81)\end{array}$ \\
\hline TTM-1 [3] & 950 & $\begin{array}{l}33{ }^{\circ} \mathrm{C} \\
235 / 473(50 \%) \\
36{ }^{\circ} \mathrm{C} \\
225 / 466(48 \%) \\
\text { HR } 1.06(95 \% \text { CI } 0.89-1.28)\end{array}$ & $\begin{array}{l}\mathrm{mRS} \text { score } 4-6 \\
33^{\circ} \mathrm{C} \\
245 / 469(52 \%) \\
36^{\circ} \mathrm{C} \\
239 / 464(52 \%) \\
\text { HR } 1.01(95 \% \text { CI } 0.87-1.14)\end{array}$ \\
\hline TTM-2 & 1900 & $\begin{array}{l}\text { Hypothermia }\left(33^{\circ} \mathrm{C}\right) \\
465 / 925(50 \%) \\
\text { Normothermia }\left(<37.8{ }^{\circ} \mathrm{C}\right) \\
446 / 925(48 \%) \\
\text { RR } 1.04(95 \% \text { CI } 0.94-1.14)\end{array}$ & $\begin{array}{l}\text { mRS score } 4-6 \\
\text { Hypothermia }\left(33^{\circ} \mathrm{C}\right) \\
488 / 881(55 \%) \\
\text { Normothermia }\left(<37.8^{\circ} \mathrm{C}\right) \\
479 / 866(55 \%) \\
\text { RR } 1.00(95 \% \text { CI } 0.92-1.09)\end{array}$ \\
\hline
\end{tabular}

HACA Hypothermia after Cardiac Arrest, TTM Targeted Temperature Management Trial (Targeted Temperature Management at $33{ }^{\circ} \mathrm{C}$ versus $36^{\circ} \mathrm{C}$ after Cardiac Arrest), TTM-2 Targeted Temperature Management Trial 2 (Hypothermia versus Normothermia after Out-of-Hospital Cardiac Arrest), $R R$ relative risk, $H R$ hazard ratio, $C I$ confidence interval hypothermia in more recent studies. The current ILCOR guidelines recommend cooling between 32 and $36{ }^{\circ} \mathrm{C}$ based on these previous studies. Local Hamilton Critical Care experts believe that there is still a role for TTM in OHCA patients. The target, however, has shifted from 33 to $36^{\circ} \mathrm{C}$, and now to the avoidance of hyperthermia $\left(<37.8^{\circ} \mathrm{C}\right)$.

\section{Bottom line}

TTM at a target temperature of $33^{\circ} \mathrm{C}$ does not provide any mortality benefit or improvement in neurological or functional outcomes over targeted normothermia in OHCA patients. Healthcare providers should continue to avoid hyperthermia $\left(>37.7^{\circ} \mathrm{C}\right)$ in these patients; however, the role of mild hypothermia and whether this could be beneficial compared to normothermia remains uncertain.

\section{Declarations}

Conflict of interest None declared.

\section{References}

1. Zeiner A, Holzer M, Sterz F, et al. Hyperthermia after cardiac arrest is associated with an unfavorable neurologic outcome. Arch Intern Med. 2001;161(16):2007-12.

2. Hypothermia after Cardiac Arrest Study Group. Mild therapeutic hypothermia to improve the neurologic outcome after cardiac arrest. N Engl J Med. 2002;346(8):549-56.

3. Nielsen N, Wetterslev J, Cronberg T, et al. Targeted temperature management at $33{ }^{\circ} \mathrm{C}$ versus $36^{\circ} \mathrm{C}$ after cardiac arrest. $\mathrm{N}$ Engl J Med. 2013;369(23):2197-206.

4. Bernard SA, Gray TW, Buist MD, et al. Treatment of comatose survivors of out-of-hospital cardiac arrest with induced hypothermia. N Engl J Med. 2002;346(8):557-63. 